\title{
Mass Spectrometric Characterization of Transferrins and Their Fragments Derived by Reduction of Disulfide Bonds
}

\author{
Mario Thevis \\ Department of Chemistry and Biochemistry, University of California at Los Angeles, Los Angeles, California, \\ USA
}

\author{
Rachel R. Ogorzalek Loo
}

Department of Biological Chemistry, University of California at Los Angeles, Los Angeles, California, USA

Joseph A. Loo

Departments of Chemistry and Biochemistry, Biological Chemistry, and the Mass Spectrometry and Proteomics Technology Center, University of California at Los Angeles, Los Angeles, California, USA

\begin{abstract}
Mass spectrometry, proteomics, and protein chemistry methods are used to characterize the cleavage products of $79 \mathrm{kDa}$ transferrin proteins induced by iron-catalyzed oxidation, including a novel C-terminal polypeptide released upon disulfide reduction. Top-down electrospray ionization tandem mass spectrometry (ESI-MS/MS) of intact multiply-charged transferrin from a variety of species (human, bovine, rabbit, chicken) performed on a quadrupole time-of-flight mass spectrometer yields multiply-charged $b_{n}$-products originating near residues 56-69 from the N-terminal region, in addition to their complementary $\mathrm{y}_{\mathrm{n}}$-products. Incubation of transferrin with reductants, such as dithiothreitol (DTT) or tris(2-carboxyethyl)-phosphine (TCEP), yields an increase in multiple charging observed by ESI-MS and an increase in molecular weight consistent with disulfide reduction. However, mammalian transferrins release a 6-8 $\mathrm{kDa}$ fragment upon disulfide reduction. Protein acetylation and MS/MS sequencing demonstrate that the fragment originates from the C-terminus of the protein, and that it is a separate polypeptide linked via three disulfide bonds to the main transferrin chain. The existence of a separate C-terminal chain is not annotated in protein sequence databases and, to date, has not been reported in the literature. Iron-catalyzed cleavage induces fragments originating from both the $\mathrm{N}$ - and C-terminus of transferrin. (J Am Soc Mass Spectrom 2003, 14, 635-647) (C 2003 American Society for Mass Spectrometry
\end{abstract}

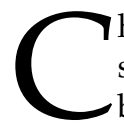
haracterization of complete protein primary structure by mass spectrometry was furthered by ionization methods such as electrospray ionization (ESI) [1] and matrix-assisted laser desorption ionization (MALDI) [2, 3]. By coupling ESI and MALDI with mass analyzers, such as quadrupole ion trap, time-of-flight (TOF), quadrupole TOF (QqTOF), and Fourier transform ion cyclotron resonance (FT-ICR), that offer improved sensitivity, resolution, accuracy, speed, and ease-of-use, protein sequence elucidation by mass spectrometry is accepted as a nearly routine strategy.

Transferrins are relatively large $79 \mathrm{kDa}$ serum glycoproteins that transport iron [4]. The primary structure is

Published online May 2, 2003

Address reprint requests to Dr. J. A. Loo, Department of Chemistry and Biochemistry, University of California at Los Angeles, Los Angeles, CA 90095-1570, USA. E-mail: jloo@chem.ucla.edu composed of two similar lobes, the N-terminal and C-terminal lobes, and each lobe contains a single iron binding site. Amino acid sequences of transferrins from several species, including human, bovine, rabbit, and chicken, show a high degree of sequence similarity. Collisionally activated dissociation (CAD) mass spectra with ESI of transferrin proteins from a variety of species was reported by Loo and Smith over one decade ago [5]. Nozzle-skimmer dissociation experiments with a quadrupole mass analyzer demonstrated that multiply charged products were generated from regions near the $\mathrm{N}$-terminus. It was reported also that upon the addition of dithiothreitol (DTT) to transferrin, a 6-8 kDa peptide appeared to be "liberated" from the intact protein. No literature reports describe a disulfide-linked peptide found in transferrin proteins, as transferrin is reported to be composed of a single 650-700 amino acid polypeptide chain with approximately 15-19 intramolecular disulfide bonds. Molecular weight measure- 
ments of the DTT-released peptides from three transferrin proteins suggested that the released product originated from the C-terminus, but the means by which it was generated remained unknown. Key to this investigation is the question of whether the released peptide arises from a heretofore uncharacterized posttranslational modification of transferrin with biological significance, or whether it is an artifact of the ironcatalyzed degradation occurring in the presence of reducing agents.

Reduction of disulfide bonds by reducing agents such as DTT and tris(2-carboxyethyl)-phosphine (TCEP) is common, with mass determinations before and after S-S reduction yielding the number of disulfide bonds [6]. Each Cys-Cys bond reduction leads to an increase of $2 \mathrm{Da}$, or multiples of the mass of the Cys-blocking agent if reductive alkylation is performed. Despite the widespread use of reducing agents in protein chemistry, dissociation of proteins into chains following reduction is not observed often, other than for proteins composed of disulfide-linked polypeptide chains (e.g., insulin).

For iron-binding proteins, however, fragmentation induced by treatment with reducing agents is well known, and is commonly utilized to localize metal ions in intact proteins [7-12]. Primarily observed in reducing environments, liberated peptides or protein fragments were revealed by 1-D gel electrophoresis, with characterization of the expelled or remaining fractions achieved by Edman degradation. The degradation reaction has been investigated in detail, and hydroxyl radicals were shown to release protein fragments. The reactions leading to hydroxyl radicals are shown in Scheme 1 . Study of reactions generating radical oxygen species such as hydroxyl radical was introduced by Haber and Weiss [13] already in 1934 with the reaction between superoxide radical and hydrogen peroxide (Scheme 1). Later studies described catalysts (such as free or chelated iron ions) needed to explain the reaction thermodynamics [14]. An alternative strategy to generate $\mathrm{OH}^{\circ}$ was demonstrated [15], based on an interaction between the ferrous-EDTA complex and hydrogen peroxide in the presence of reducing agents such as ascor-

$$
\begin{aligned}
& \mathrm{O}_{2}^{-{ }^{-}}+\mathrm{Fe}^{3+} \rightarrow \mathrm{O}_{2}+\mathrm{Fe}^{2+} \\
& \mathrm{Fe}^{2+}+\mathrm{H}_{2} \mathrm{O}_{2} \rightarrow \mathrm{Fe}^{3+}+\mathrm{OH}+\mathrm{OH}^{-} \\
& \mathrm{Fe}^{2+}-\mathrm{EDTA}+\mathrm{H}_{2} \mathrm{O}_{2} \rightarrow \\
& \mathrm{Fe}^{3+}-\mathrm{EDTA}+\mathrm{OH}^{-}+\mathrm{OH}^{-} \\
& \mathrm{O}_{2}{ }^{-}+\mathrm{H}_{2} \mathrm{O}_{2} \rightarrow \mathrm{O}_{2}+\mathrm{OH}^{-}+\mathrm{OH}^{-}
\end{aligned}
$$

Scheme 1. Iron-catalyzed redox reactions eq (1) and eq (2), ferrous-EDTA-catalyzed redox reaction eq (3) and the HaberWeiss net reaction eq (4) generating hydroxyl radical. Superoxide can be replaced by other reagents such as ascorbate or DTT, which reduce the iron from ferric to ferrous oxidation status after catalysis of hydrogen peroxide. bate or dithiothreitol. Thus, hydroxyl radicals can be generated independent of superoxide [16]. The capability of protein-bound iron to catalyze ROS formation for transferrin was investigated [15, 17], but controversy exists as to whether iron ions introduced into the protein lobes promote the production of $\mathrm{OH}^{-}$[18]. Today apo-transferrin is used in iron-binding therapy to reduce hydroxyl radical formation [19].

Although the most practiced method for MS-based protein sequencing combines proteolytic cleavage of the intact protein with subsequent sequencing of the resulting peptide fragments by tandem mass spectrometry (MS/MS), especially with LC-MS/MS and by MALDIMS/MS, there is value in the direct fragmentation of the intact gas phase protein. This strategy can expose and pinpoint sites of posttranslational modification and sequence mutation. Moreover, the fragmentation pattern from CAD of large proteins can generate sufficient information for identification from sequence databases, particularly when combined with accurate mass measurements of both the intact molecule and its product ions [20-22]. Enhanced efficiency for CAD of multiply charged molecules [23] generates multiply charged sequence-informative product ions from ESI-produced gas phase ions for biomolecules as large as $66 \mathrm{kDa}$ serum albumin proteins [24]. CAD-MS of multiply charged proteins often yield multiply charged products. The ESI-MS/MS products from small proteins, such as $8.6 \mathrm{kDa}$ ubiquitin $[25,26]$ and $13 \mathrm{kDa}$ ribonuclease A [27] to larger proteins such as $29 \mathrm{kDa}$ carbonic anhydrase [26] and $66 \mathrm{kDa}$ serum albumin [24], can be interpreted as resulting from either/or the $\mathrm{N}$ - or C-termini or from cleavage near proline residues, even with data from low resolving power analyzers. However, the determination of precursor and product charge state is amenable to higher resolving power instruments such as FT-ICR and QqTOF mass spectrometers, yielding data that is interpretable unambiguously [28]. This "top down sequencing" approach, as coined by McLafferty and co-workers [29], can yield substantial sequence information by fragmenting intact proteins directly, especially from FTICR-MS armed with infrared multiphoton dissociation (IRMPD) [30] or electron capture dissociation (ECD) [29, 31-33].

Building upon the previous top-down sequencing study [5], the CAD top-down sequencing behavior of human and bovine transferrin proteins and their behavior upon disulfide bond reduction are investigated further with a QqTOF mass spectrometer. Both N- and $\mathrm{C}$-terminal fragments from the proteins (apo- and holotransferrin) were examined upon reduction with DTT or TCEP, and were characterized by tandem mass spectrometry. Protein chemistry and MS methods were used to investigate whether cleavage of transferrins upon reduction involved iron-catalysis or liberation of a free polypeptide chain. 


\section{Experimental}

\section{Chemicals and Proteins}

Ammonium bicarbonate (99\%), acetic anhydride (98\%), human and bovine apo- and holo-transferrins were purchased from Sigma (St. Louis, MO). Methanol and acetonitrile (both HPLC grade) were obtained from Merck (Darmstadt, Germany). Dithiothreitol was from Bio-Rad (Hercules, CA) and tris-(2-carboxyethyl)-phosphine hydrochloride was supplied by Pierce (Rockford, IL). Modified trypsin (sequence grade) was purchased from Promega (Madison, WI).

\section{Sample Preparation}

Stock solutions of transferrins were prepared in deionized water at $5 \mu \mathrm{g} / \mu \mathrm{L}$. A volume of $10 \mu \mathrm{L}$ of $10 \mathrm{mM}$ DTT (in $50 \mathrm{mM}$ ammonium bicarbonate) or $350 \mathrm{mM}$ TCEP-HCl was added to $10 \mu \mathrm{L}$ of each transferrin solution. The mixtures were incubated overnight at room temperature. After the electrophoretic separation and visualization of transferrin degradation products, trypsin digestion was performed in-gel according to the protocol published by Shevchenko et al. [34]. DTTreduced product peptides were removed from transferrin proteins by centrifugal ultrafiltration through a Microcon YM-30 filter at $6000 \mathrm{rpm}$ for $15 \mathrm{~min}$ followed by additional washes with deionized water. Transferrin was acetylated by solving $1 \mathrm{nmol}$ of protein in $20 \mu \mathrm{L}$ of $50 \mathrm{mM}$ ammonium bicarbonate $(\mathrm{pH}$ 8) with addition of $50 \mu \mathrm{L}$ of $30 \%$ acetic anhydride in methanol. The reaction mixture was held at room temperature for $2 \mathrm{~h}$ and evaporated to dryness by vacuum centrifugation at $60{ }^{\circ} \mathrm{C}$.

\section{Gel Electrophoresis}

Approximately $10 \mu \mathrm{g}$ of the proteins treated with DTT were loaded onto NuPage bis-tris (Invitrogen, Carlsbad, CA) precast polyacrylamide gels (10\%, $1 \mathrm{~mm}$ thickness), and one dimensional gel electrophoresis was performed under reducing conditions using 2-(N-morpholino) ethane sulfonic acid (MES) as running buffer. The bis-tris gels employed the NuPage formulations of LDS sample buffer (lithium dodecylsulfate), reducing agent (DTT), and running buffer anti-oxidant. After fixing, staining was performed with GelCode Blue (Pierce, Rockford, IL) stain reagent according to the recommended protocol.

\section{Mass Spectrometry}

Mass spectra of chemically degraded proteins were recorded on an Applied Biosystems (Foster City, CA) Voyager DE STR MALDI-TOF mass spectrometer, a QStar Pulsar-i (QqTOF) equipped with a nanoelectrospray (Protana, Odense, Denmark) interface and an Agilent (Palo Alto, CA) nano-LC system interfaced to an 1100 Series LC/MSD trap. For MALDI, sinapinic acid (saturated solution) in 50\% acetonitrile containing $0.1 \%$ TFA was used as matrix. Peptide product ion spectra were generated by the ion trap mass spectrometer and identification was accomplished utilizing the Mascot database search engine (Matrix Science, London, UK). Product ion spectra from intact protein molecules were recorded by nanoelectrospray on the QqTOF mass spectrometer using solutions of acetonitrile/water (1:1, vol:vol) containing $1 \%$ formic acid. Protein solutions (1-2 $\mu \mathrm{L}$ ) were loaded into borosilicate glass capillaries (Protana). Nitrogen was employed as collision gas. The QStar Pulsar- $i$ uses a LINAC (linear accelerator) collision cell design that operates at approximately 10 mTorr. A laboratory-frame collision energy of $+1800 \mathrm{~V}$ was used for the MS/MS experiments with the intact transferrin molecules.

\section{Results and Discussion}

\section{Mass Spectrometry and Tandem Mass Spectro- metry of Intact Transferrins}

ESI-MS of transferrin proteins generates a series of multiply charged molecules that are consistent for a protein of over $79 \mathrm{kDa}$ (Figure 1a, measured molecular weight for human transferrin is $79562 \mathrm{Da}$ ). The polypeptide sequence codes for a molecular weight of 75.2 and $75.8 \mathrm{kDa}$ for the human and bovine species, respectively, and the remaining mass is carried by $\mathrm{O}-$ and N-linked glycosylation. As reported over 10 years ago for transferrin [5], sequence informative product ions can be generated by increasing the energy in the atmosphere/vacuum interface, as shown in the mass spectra of Figure $1 \mathrm{~b}$ and Figure 2. CAD-MS of the intact transferrin protein yields multiply charged b-products originating near residues 56-69 and with charges $\mathrm{z}=$ 4-7. Serum albumin proteins show similar behavior upon $\mathrm{CAD}$, as multiply charged b-ions from residues 25-35 are produced [24]. Transferrin proteins from different species, such as human, bovine, rabbit, and chicken yield similar MS and CAD-MS spectra, with the fragmentation patterns reflecting the differences in sequence [5]. With an analyzer of moderate resolving power, such as the QqTOF, product ion charge states up to $7+$ can be determined directly from the spacing between isotope peaks, as shown in Figure 1b. Moreover, with high sensitivity analyzers such as the QqTOF, ESI-MS/MS spectra of individual transferrin charge states can be obtained, providing data interpretation advantages over the nozzle-skimmer dissociations of a decade ago [5]. This capability is demonstrated in Figure 3, with the MS/MS spectrum from 36+ charged human apo-transferrin. The same b-ions are observed as in the CAD mass spectrum generated in the atmosphere/vacuum interface (Figure 2). In addition, a series of larger products appears at higher $\mathrm{m} / \mathrm{z}$ above the precursor molecule position. The deconvoluted molecular weights of these fragments (of charge $24+$ to 


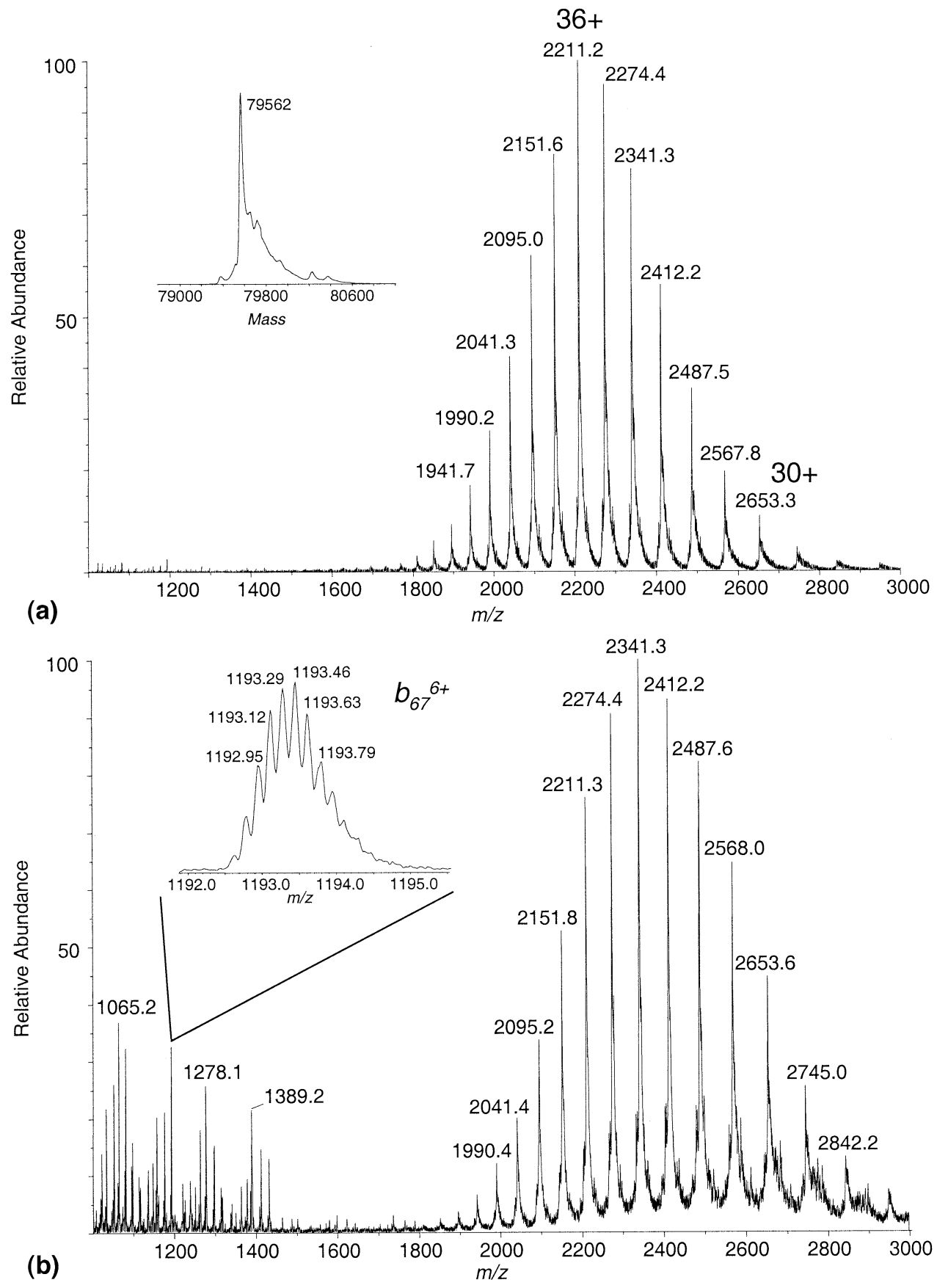

Figure 1. ESI-mass spectrum of human apo-transferrin obtained with a declustering potential of (a) $25 \mathrm{~V}$ and (b) $120 \mathrm{~V}$. The inset in (a) shows the deconvolution mass spectrum. The inset in (b) expands the peak at $m / z 1193$, revealing resolved isotopes for the $b_{67}^{6+}$ product ion.

$30+$ ) range in size from $69-73 \mathrm{kDa}$ that are consistent for the $\mathrm{y}_{\mathrm{n}}$-complement to the $\mathrm{b}_{\mathrm{n}}$-products observed in the lower $\mathrm{m} / \mathrm{z}$ region of the spectrum. For example, the products $b_{59}^{6+}$ at $m / z 1065$ and $\mathrm{y}_{620}^{30+}$ at $\mathrm{m} / \mathrm{z} 2440$ are observed as complementary product ion pairs for the 679 residue human transferrin (Figure 3). Other products observed that do not display complementary ions may result from multiple fragmentation reactions [26].

As demonstrated by others, the fragmentation pattern generated from CAD of intact proteins can be used as a means for securing protein identity [20, 35, 36]. Consider the CAD-MS spectrum of human transferrin displayed in Figure 2. From the molecular masses of the product ions, the sequence string ADAVT(I/L)DAG(I/L)VY can be constructed (Table 1). Three internet-available protein sequence searching programs identified the protein as human transferrin from the forwarded sequence string: MS-pattern (prospector.ucsf.edu/ucsfhtml4.0/mspattern. $\mathrm{htm}$ ) as part of the Protein Prospector suite of programs developed by the University of California-San Francisco, 

VPDKTVRWCA VSEHEATKCQ SFRDHMKSVI PSDGPSVACV KKASYLDCIR

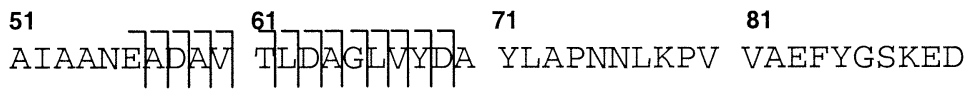

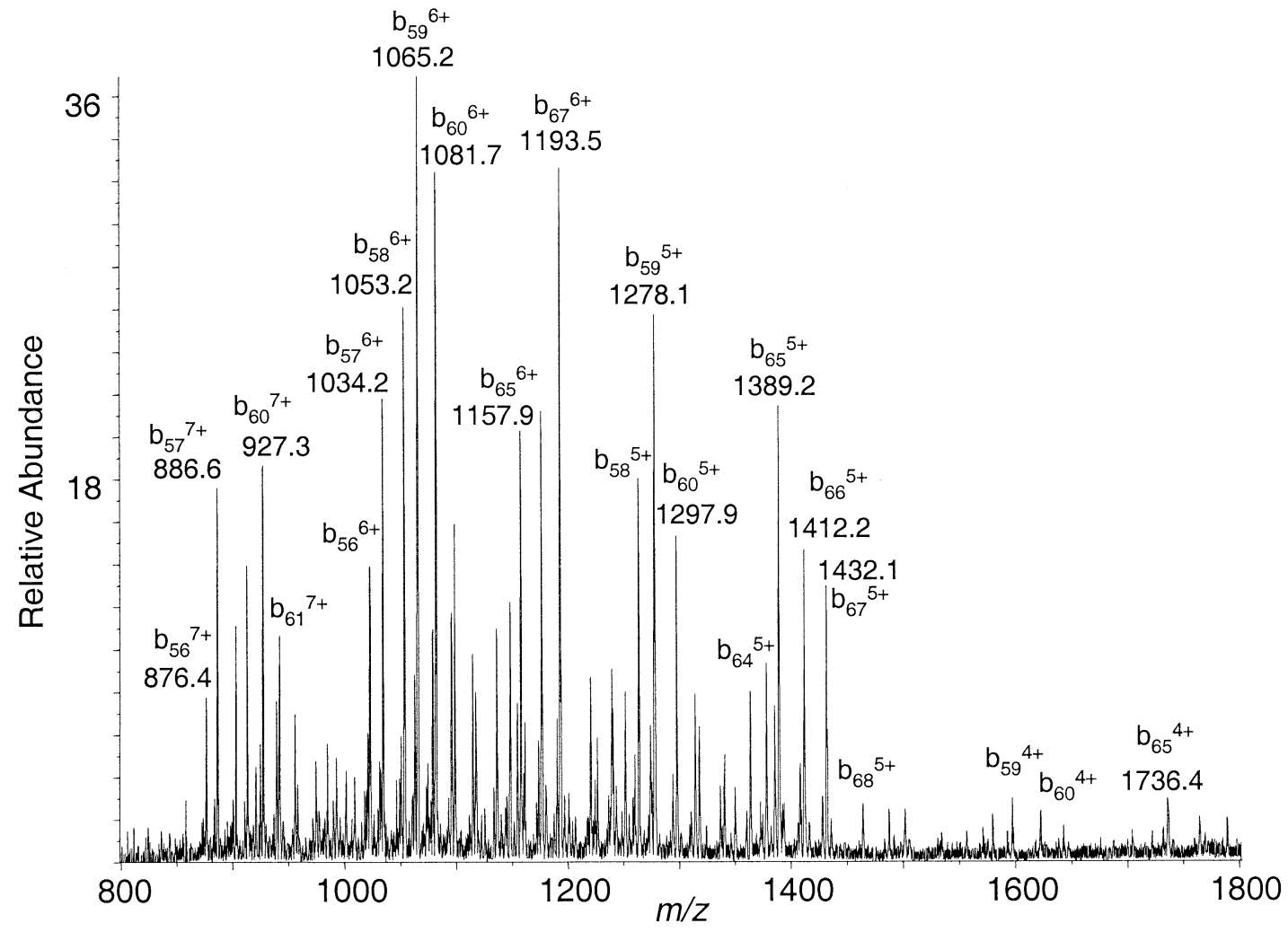

Figure 2. Product ions of human apo-transferrin generated by applying a $120 \mathrm{~V}$ declustering potential across the atmospheric pressure/vacuum ESI interface.

Peptide Search (www.narrador.embl-heidelberg.de/ GroupPages/PageLink/peptidesearchpage.html) developed by the European Molecular Biology Laboratory, and the Rockefeller University/Proteometrics-developed ProteinInfo (129.85.19.192/prowl/proteininfo.html) as part of the PROWL software. It is likely that this strategy will be employed more often in proteomics as MS and MS/MS sensitivity improve for intact proteins analysis.

It is interesting to speculate on the nature of the cleavage pattern. The N-terminal residues 1-60 appear to be exposed based on the crystal structures for porcine and rabbit serum transferrin (see Hall et al. [37] and Protein Data Bank entry 1h76, www.rcsb.org/pdb/). It is doubtful that the native structure is retained in these gas phase experiments, because the acidic solution $(\mathrm{pH}$ 3) used for the ESI-MS experiments should denature the protein. Nevertheless, elements of the higher order structure may survive, particularly if constrained by disulfide bridges. For human transferrin, disulfide bonds between $\mathrm{Cys}_{9}-\mathrm{Cys}_{48}$ and $\mathrm{Cys}_{19}-\mathrm{Cys}_{39}$ may play a role in retaining the general shape and accessibility of the N-terminal region.

\section{Disulfide-Reduced Human and Bovine Apo-Transferrin}

Apo-transferrins of human and bovine origin, when exposed to reducing agents such as DTT or TCEP-HCl, liberate protein fragments, as visualized by 1-D SDSPAGE, shown in Figure 4. In Figure 5, the MALDI-TOF mass spectra of human and bovine apo-transferrin before and after reductive degradation by DTT are presented. For human apo-transferrin, an abundant

Table 1. Product ion masses from a CAD-mass spectrum of human transferrin

\begin{tabular}{lccccccccccccc}
\hline Mass & 6128.01 & 6199.49 & 6314.69 & 6386.08 & 6484.88 & 6586.08 & 6699.33 & 6814.38 & 6885.40 & 6942.64 & 7055.81 & 7154.99 & 7318.51 \\
$\Delta$ Mass & 71.48 & 115.20 & 71.39 & 98.80 & 101.20 & 113.25 & 115.05 & 71.02 & 57.24 & 113.17 & 99.18 & 163.52 & V \\
Sequence & $\mathrm{A}$ & $\mathrm{D}$ & $\mathrm{A}$ & $\mathrm{V}$ & $\mathrm{T}$ & $\mathrm{L}$ & $\mathrm{D}$ & $\mathrm{A}$ & $\mathrm{G}$ & $\mathrm{L}$ & $\mathrm{V}$ & $\mathrm{Y}$ & \\
\hline
\end{tabular}




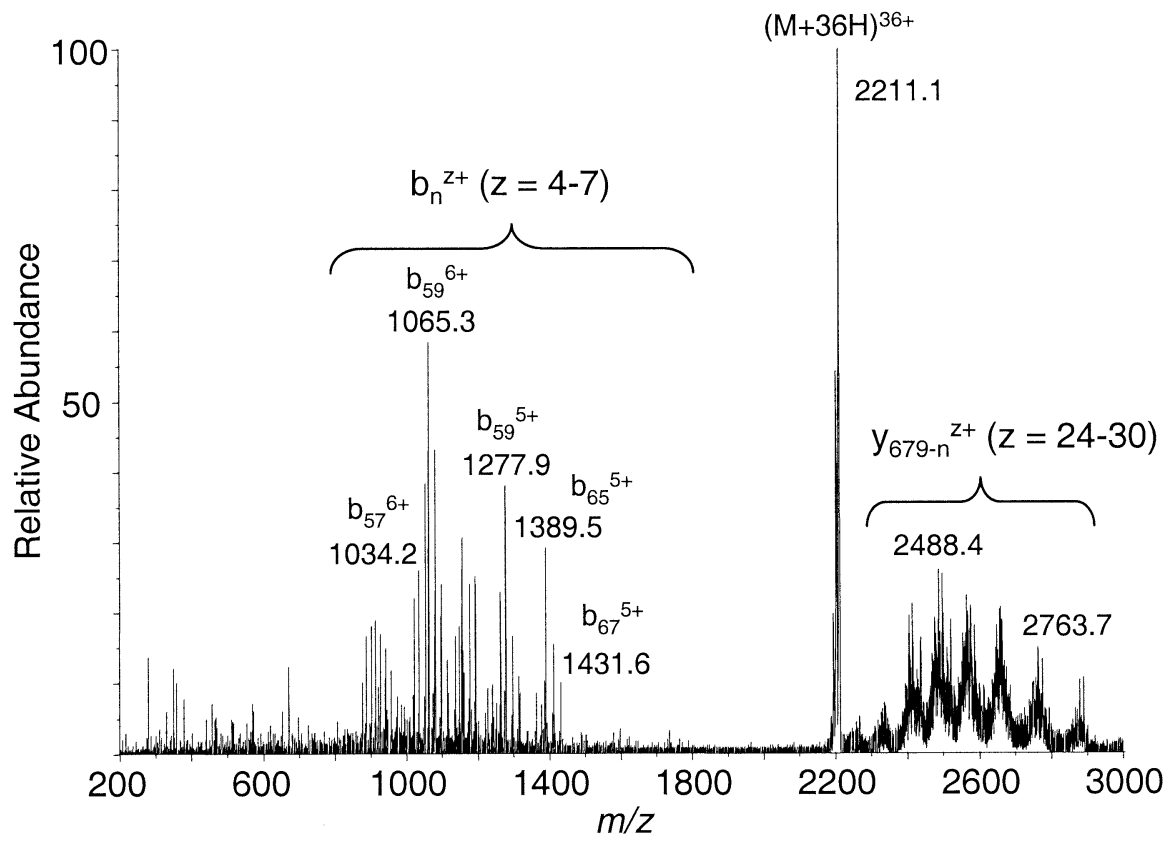

Figure 3. ESI-MS/MS spectrum of $(\mathrm{M}+36 \mathrm{H})^{36+}$ molecules $(\mathrm{m} / z$ 2211) of human apo-transferrin.

peak at $m / z 6485$ is observed in addition to intense signals for the singly and doubly charged intact protein ( $m / z 79,345$ and 39,784, respectively) (Figure 5b). The sum of the C-terminal 56 amino acid residues (624-679, Figure 6) represents a theoretical peptide of average molecular weight $6485.4 \mathrm{Da}$, consistent with the MALDI-MS measurement.

DTT treatment of human apo-transferrin and analysis by ESI-QqTOF mass spectrometry reveals increases in overall multiple charging and in molecular weight,

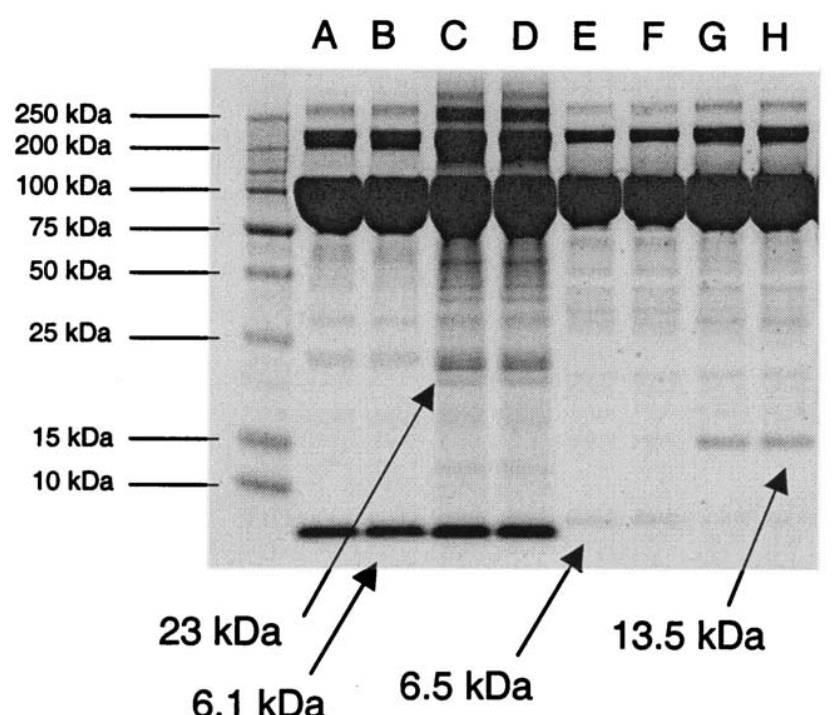

Figure 4. 1-D SDS-PAGE gel of disulfide-reduced human and bovine apo- and holo-transferrins, stained with Coomassie Blue: Bovine apo-transferrin [lanes (a) and b)], bovine holo-transferrin [lanes (c) and (d)], human apo-transferrin [lanes (e) and (f)], and human holo-transferrin [lanes (g) and (h)]. Equal amounts $(10 \mu \mathrm{g})$ of protein were loaded onto each lane. consistent for the ESI-MS of disulfide-reduced proteins [6]. The measured molecular weight of 79,593 Da for the reduced protein is $31 \mathrm{Da}$ higher than that measured for the oxidized protein $(79,562 \mathrm{Da})$. Similarly, molecular weights of 77,982 Da and 78,016 Da were measured for the bovine transferrin oxidized and reduced forms, respectively. Human transferrin has 19 disulfide bonds and bovine transferrin has 18 disulfide bonds. A more precise estimate of the number of disulfide bonds could be obtained by alkylating the free thiol side-chains to reduce the mass accuracy requirement (i.e., a mass increase of 58 Da for generation of carboxymethylcysteine with iodoacetic acid for each Cys-residue). Additionally, multiply charged ions at $\mathrm{m} / \mathrm{z} 649.5(\mathrm{M}+$ $10 \mathrm{H})^{10+}$ and $721.5(\mathrm{M}+9 \mathrm{H})^{9+}$ affording a calculated mass of 6485.6 are observed (Figure $7 \mathrm{a}$ ), consistent with the MALDI mass spectrum. Further evidence of the identity of the DTT-released fragment was obtained from the product ion spectrum of the $10+$ charged precursor ion ( $m / z$ 649.5), shown in Figure $7 \mathrm{~b}$. Abundant ions could be assigned to calculated fragment masses for the predicted C-terminal peptide of human transferrin.

With bovine apo-transferrin (Figures 4 and 5d), the putative C-terminal peptide liberated was significantly more abundant than in the case of human apo-transferrin. Here, the 53 amino acid residues 633-685 (Figure 6) with a theoretical average molecular mass of 6063.0 $\mathrm{Da}$ were released, producing signals in the MALDI mass spectrum at $\mathrm{m} / \mathrm{z} 6064$ (singly charged monomer) and 12,128 (singly charged dimer). Furthermore, peaks for the intact protein were detected at $m / z$ 78,032 (singly charged) and 39,085 (doubly charged), as well as for their counterparts sans the C-terminus at $\mathrm{m} / \mathrm{z} 71,983$ (singly charged) and 35,934 (doubly charged). Higher 
(a)
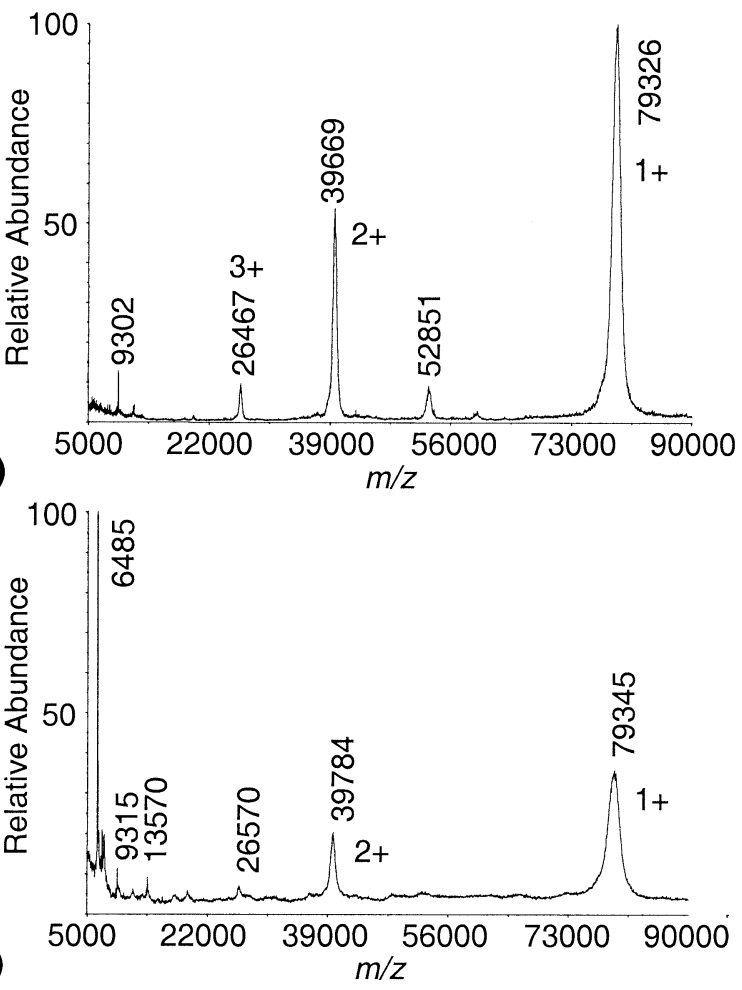
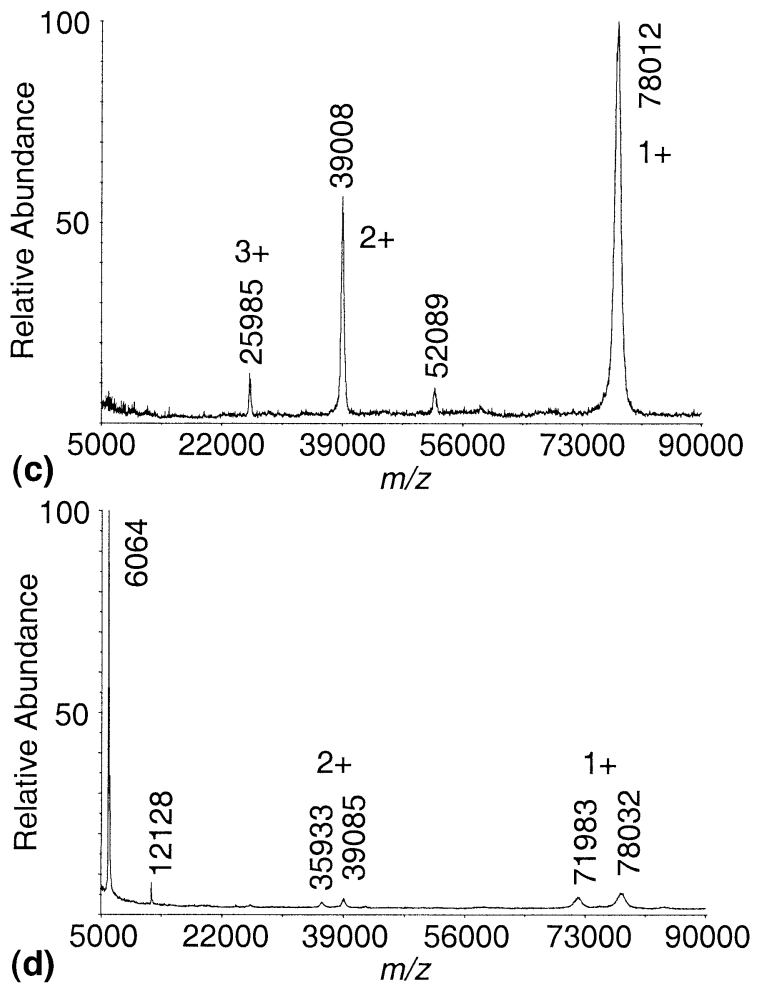

Figure 5. MALDI-TOF mass spectra of (a) human apo-transferrin before and (b) after treatment with DTT; (c) bovine apo-transferrin before and (d) after treatment with DTT. The $1+, 2+$, and $3+$ charged protein molecules are labeled.

precision mass spectra were recorded by ESI-QqTOF mass spectrometry as shown in Figure 8a. The liberated C-terminal peptide mass was determined to be 6062.9 $\mathrm{Da}$ and the product ion scan of the $(\mathrm{M}+8 \mathrm{H})^{8+}$ molecule at $\mathrm{m} / \mathrm{z} 758.8$ confirmed the predicted amino acid composition (Figure $8 b$ ). In our previous studies, disulfide reduction of 676 amino acid rabbit transferrin liberated a peptide of measured molecular weight

human transferrin

\begin{tabular}{|c|c|c|c|}
\hline 581 & 591 & 601 & 611 \\
\hline RAPNHAVVTR & KDKEACVHKI & LRQQQHLFGS & NVTDCSGNFC \\
\hline 621 & 631 & 641 & 651 \\
\hline LFRSETKDLL & FRDDTVCLAK & LHDRNTYEKY & LGEEYVKAVG \\
\hline 11 & סקימידתמיד & & \\
\hline
\end{tabular}

\begin{tabular}{llll}
\multicolumn{4}{c}{ bovine transferrin } \\
581 & 591 & 601 & 611 \\
AENCHLARGP & NHAVVSRKDK & ATCVEKILNK & QQDDFGKSVT \\
& & & \\
621 & 631 & 641 & 651 \\
DCTSNFCLFQ & SNSKDLLFRD & DTKCLASIAK & KTYDSYLGDD \\
\cline { 2 - 3 } & & & \\
661 & 671 & 681 & \\
YVRAMTNLRQ & CSTSKLLEAC & TFHKP & \\
\hline
\end{tabular}

Figure 6. C-terminal residues of human and bovine transferrins. Residues highlighted in bold and underlined represent the peptide released upon disulfide reduction.
7752.6 Da, consistent with a C-terminal peptide composed of residues 610-676 (theoretical molecular weight $7753.0 \mathrm{Da}$ ) [5]. In contrast, a similar product from disulfide reduction was not observed from chicken (ovo)transferrin.

Remaining unclear is the mechanism for release of the C-terminal fragment upon disulfide reduction. Is the C-terminal portion a separate polypeptide chain secured to the main transferrin chain by one-to-three intermolecular disulfide bonds (as there are three Cys residues in the released C-terminal peptide)? No previous literature reports suggest this possibility. Alternatively, iron-catalyzed fragmentation of iron-bound proteins has been studied for a number of systems. Both mechanisms were investigated for transferrin proteins.

\section{Iron-Catalyzed Cleavage of Transferrin}

The mechanism of iron-catalyzed protein degradation has been investigated in detail, and radical oxygen species (ROS, e.g., hydroxyl radicals) were proposed to be the reactive agent. Thus, the influence of DTT on iron-saturated human and bovine transferrins was investigated analogically. Aliquots of human and bovine holo-transferrins were mixed with $10 \mathrm{mM}$ DTT and maintained at room temperature for $14 \mathrm{~h}$. The resulting MALDI-TOF mass spectra are shown in Figure 9. For human holo-transferrin (Figure 9a), two intense signals at $m / z 13,410$ and 13,567 were observed, along with the 

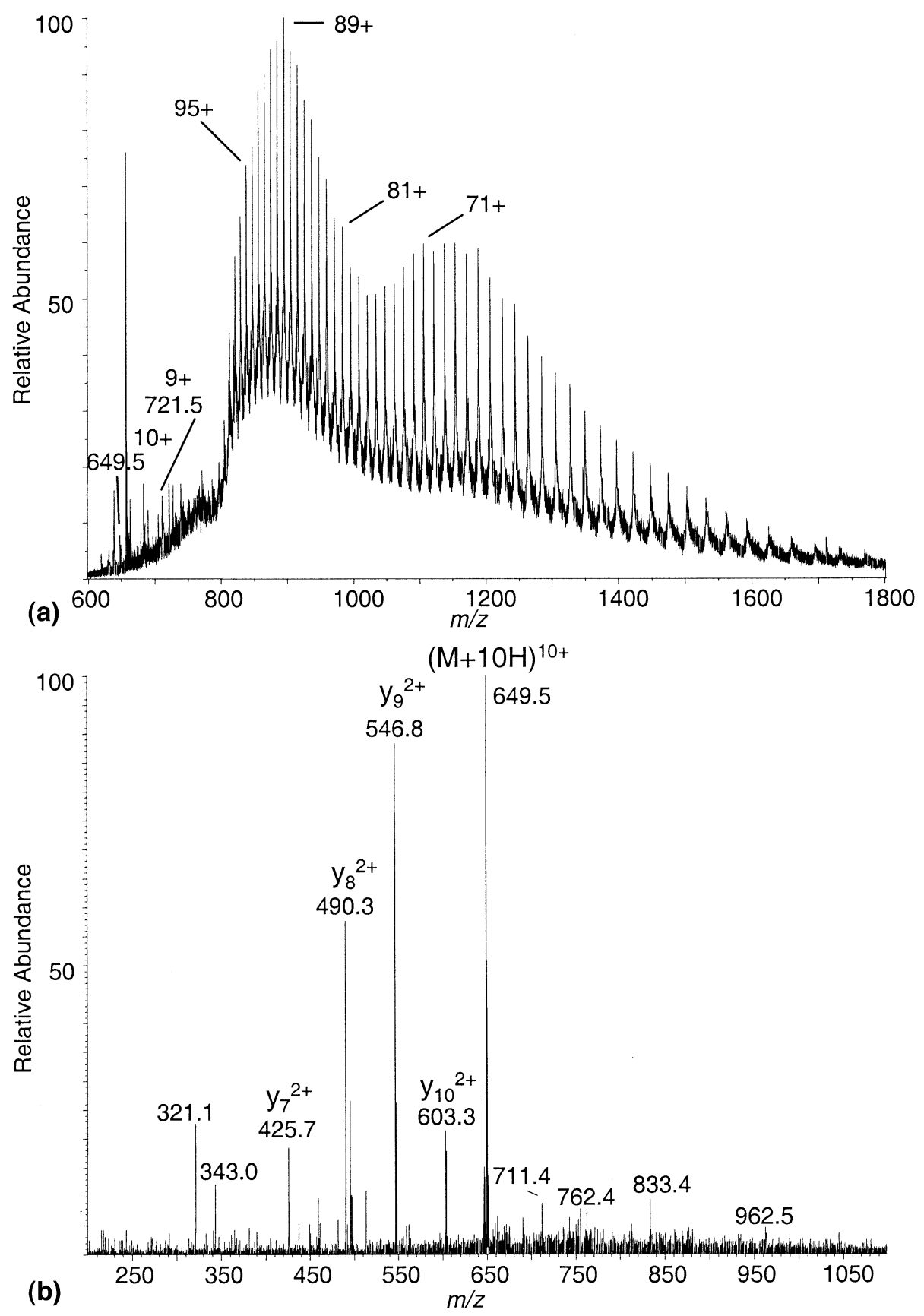

Figure 7. (a) ESI-MS spectrum of human apo-transferrin after treatment with DTT, and (b) product ion spectrum of the $(\mathrm{M}+10 \mathrm{H})^{10+}$ molecule $(\mathrm{m} / \mathrm{z}$ 649.5) from the released C-terminal fragment.

$\mathrm{m} / \mathrm{z} 6486$ signal observed from analysis of the reduced iron-free analogue. The N-terminal amino acids 1-124 constitute a mass of 13,560 Da, terminating in $\mathrm{Arg}_{124}$, the potential location of the counterion (bicarbonate) to the N-terminal lobe-bound iron. Cleavage of human transferrin either $\mathrm{N}$ - or C-terminal to $\mathrm{Arg}_{124}$ would yield peptides of 13,404 or $13,560 \mathrm{Da}$, respectively, consistent with the MALDI-TOF mass spectrum shown in Figure 9a. To confirm the N-terminal origin of these fragments, the sample was loaded onto a 1-D SDSPAGE gel and the protein fractions were separated
(Figure 4, Lane $\mathrm{G}$ and $\mathrm{H}$ ). The band at $13.5 \mathrm{kDa}$ was excised, destained, and the entrapped protein was digested with trypsin. The resulting peptides were analyzed by MALDI-TOF MS and LC-iontrap MS/MS, securing the $\mathrm{N}$-terminal origin of the $13.5 \mathrm{kDa}$ fragment by confirming peptides comprising the amino acid sequences 28-41, 51-88, 89-102 and 104-113 (data not shown). Because this fragment was not observed with human apo-transferrin, the participation of iron in this cleavage is likely. However, it remains still to clarify whether the cleaved peptide bond $\left(\operatorname{Arg}_{124}\right)$ and its 

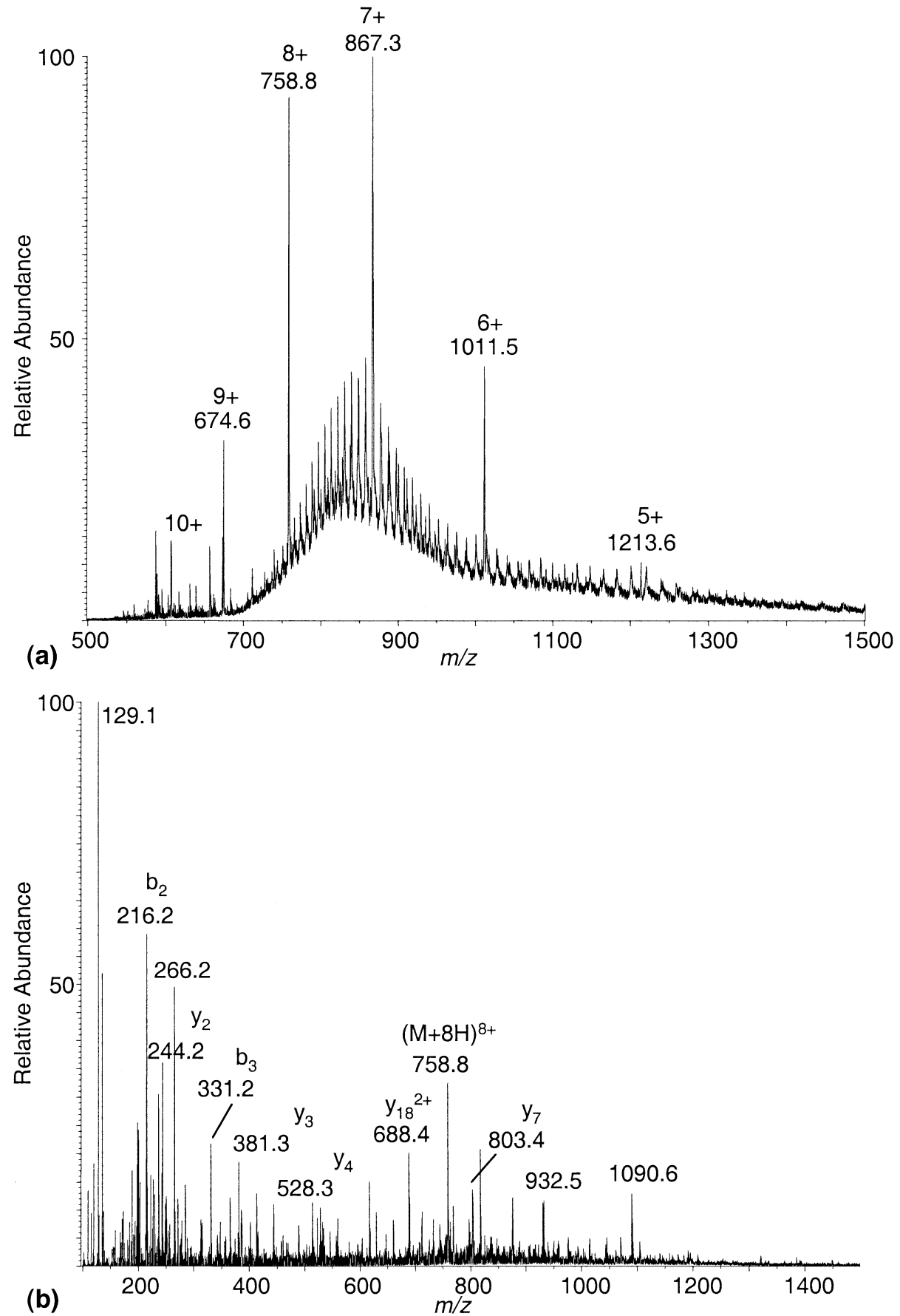

Figure 8. (a) ESI-MS spectrum of bovine apo-transferrin after treatment with DTT, and (b) product ion spectrum of the $(\mathrm{M}+8 \mathrm{H})^{8+}$ molecule $(\mathrm{m} / \mathrm{z}$ 758.8) from the released C-terminal fragment.

match to the predicted counterion bicarbonate is biologically relevant, or merely a coincidence. If the former, the iron-catalyzed reaction would have to occur rapidly enough that sufficient transferrin higher order structure had been retained.

Bovine holo-transferrin treated with DTT gave rise to the MALDI-TOF mass spectrum shown in Figure $9 \mathrm{~b}$. Signal corresponding to the C-terminal fragment (amino acids 633-685) known from bovine apo-transferrin appears less intense compared to Figure $5 d$, but the $1-D$
SDS-PAGE gel in Figure 4 (Lanes $\mathrm{c}$ and d) stained the $6.1 \mathrm{kDa}$ band at approximately equal intensity as those of the bovine apo-transferrin (Figure 4, Lanes a and b). In addition, two bands at approximately $22 \mathrm{kDa}$ are observed more easily in the bovine holo-transferrin lane compared to the bovine apo-transferrin lane. At least three separate experiments with different sample preparations confirmed that they appeared reproducibly. That the $22 \mathrm{kDa}$ band was observed from the apoprotein (albeit at lower abundance) may reflect residual 

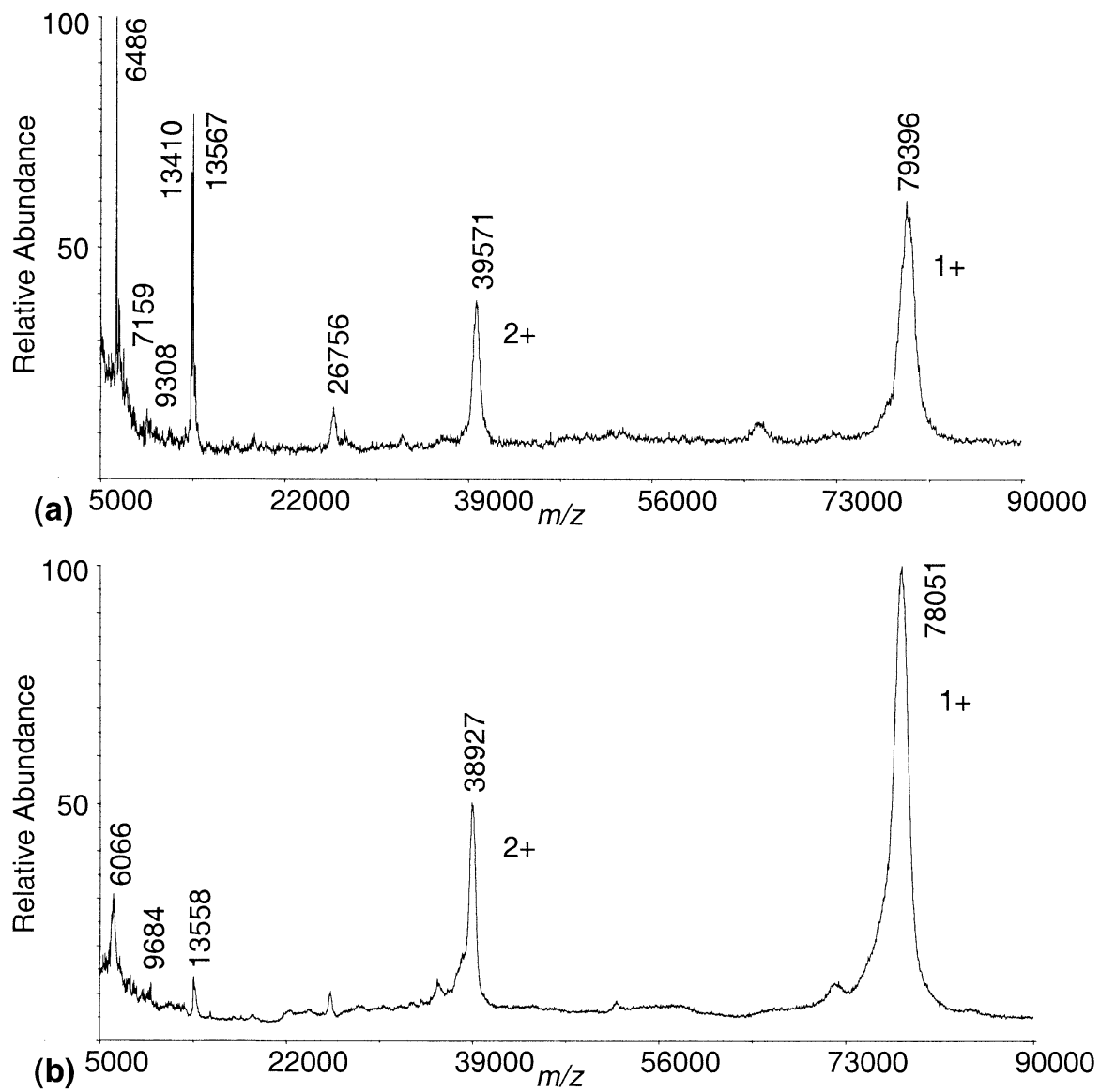

Figure 9. MALDI-TOF mass spectra of (a) human holo-transferrin and (b) bovine holo-transferrin after treatment with DTT. The $1+$ and $2+$ charged protein molecules are labeled.

iron contamination in the protein. Excision of these adjacent bands followed by tryptic digestion and LCMS/MS analysis verified peptides originating from the N-terminal residues 50-87, 88-101, 124-133, and 137147 , as well as two from the C-terminus (amino acid sequences 521-529 and 652-663, data not shown), demonstrating co-migration of two comparably sized peptides on the 1-D gel. Here, it was not possible to specify the cleavage sites precisely, as the determination of the molecular weight for these fragments was not accomplished by mass spectrometry, but estimated only by gel electrophoresis.

Thus, it appears that iron-catalyzed cleavage products can be observed upon disulfide reduction of holotransferrin, but the transferrin products are not the same 6-8 kDa species as observed from apo-transferrin. The C-terminal peptide is released in about equal amounts with and without iron saturation for both the human and bovine proteins. Because hydroxyl radicals are very reactive with lifetimes of several nanoseconds in aqueous solution, and from a radius of diffusion of approximately $20 \AA[38,39]$, cleavage catalyzed by iron should occur only in close proximity to the point of hydroxyl radical generation, i.e., the transition metal ion. Predicted iron-binding sites of human transferrin (residues $\mathrm{Asp}_{63}, \mathrm{Tyr}_{95}, \mathrm{Tyr}_{188}, \mathrm{His}_{249}$ for the N-terminal lobe, and $\mathrm{Asp}_{392}, \mathrm{Tyr}_{426}, \mathrm{Tyr}_{517}, \mathrm{His}_{585}$ for the C-terminal lobe) and bovine transferrin (residues $\mathrm{Asp}_{62}, \mathrm{Tyr}_{94}$, $\mathrm{Tyr}_{192}, \mathrm{His}_{253}$ for the N-terminal lobe, and $\mathrm{Asp}_{395}$, $\mathrm{Tyr}_{430}, \mathrm{Tyr}_{524}, \mathrm{His}_{592}$ for the C-terminal lobe) are too distant from the identified C-terminal cleavage sites; the lifetime of ROS such as hydroxyl radicals does not suffice to explain the remote position of the bonds cleaved, were the iron still located at its position in the native structure. The reproducible liberation from human, bovine, and rabbit transferrins (replete and depleted of iron) suggests that iron, released by reduction of transferrin, does not cause the protein degradation responsible for the generation of the 6-8 $\mathrm{kDa}$ polypeptide.

\section{Investigation of a C-Terminal Disulfide-Linked Intermolecular Transferrin Polypeptide}

Assuming that three cysteines within the expelled Cterminal peptide had originally been cystine-linked to the remaining transferrin chain, evidence for a nick in the primary sequence prior to disulfide bond reduction was sought. First, we confirmed that DTT treatment of reduced full length transferrin did not release additional $6 \mathrm{kDa}$ peptide. After bovine apo-transferrin was 


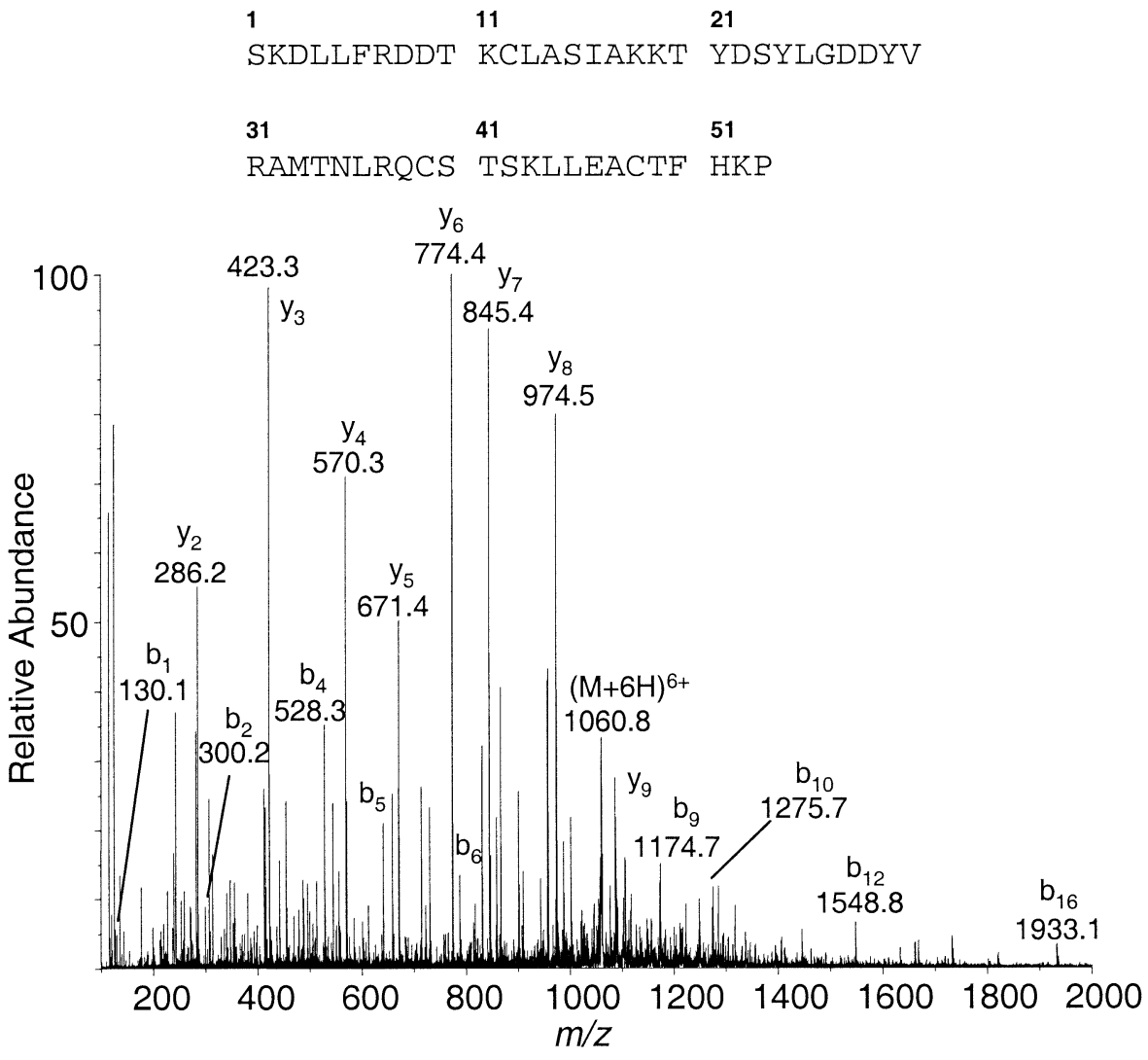

Figure 10. ESI-MS/MS spectrum of $m / z 1060.8$ (6+ charge) of the acetylated C-terminal peptide of bovine transferrin released by DTT reduction of disulfide bonds.

reduced with DTT, the $6.1 \mathrm{kDa}$ fragment was filtered out of the reaction mixture by multiple centrifugal filtrations through a $30 \mathrm{kDa}$ Microcon filter. Peptide removal was confirmed by MALDI-MS of the retentate. Additional treatment of DTT to the retentate (containing both full length and C-terminally truncated transferrin) did not yield additional $6.1 \mathrm{kDa}$ products (data not shown).

To obtain evidence that a separate polypeptide chain was bound to transferrin via disulfide linkages, acetylation of bovine transferrin prior to disulfide reduction was performed. By addition of acetic anhydride (in methanol) to a transferrin solution, the primary amino groups of lysines as well as the $\mathrm{N}$-terminus of the protein are acetylated. Were a chain interruption present, an additional $\mathrm{N}$-terminus would be introduced into the putative polypeptide, also eligible for acetylation. The C-terminus (amino acids 633-685) of bovine transferrin comprises six lysine residues, and thus the molecular weight should increase by $252 \mathrm{Da}$ upon acetylation, but by $294 \mathrm{Da}$ in the case of a "nick" presenting with a second N-terminus (+42 Da). ESI-MS analysis of acetylated, disulfide-reduced bovine apotransferrin afforded the accurate mass of the liberated C-terminus as $6358.6 \mathrm{Da}$, consistent with seven acetyl groups in the released peptide. The MS/MS spectrum of the $(\mathrm{M}+6 \mathrm{H})^{6+}$ molecule at $m / z 1060.8$ gave rise to $\mathrm{b}$ and $y$-ion series products that unambiguously demon- strated the acetylation of a second $\mathrm{N}$-terminus of bovine transferrin (Figure 10), and that the nick was present in a fraction of the transferrin molecules, prior to disulfide reduction. From the 1-D SDS gels (Figure 4) and the ESI mass spectra (Figures 7 and 8), very rough quantitative estimations of the C-terminally truncated protein relative to the total protein amount are 5 and $30 \%$ for human and bovine transferrins, respectively.

To our knowledge, the elimination of C-terminal fragments from transferrins upon disulfide reduction and the presence of a C-terminal peptide disulfidelinked intramolecularly to the main transferrin polypeptide chain have not been described in the literature, other than our original report at the ASMS conference over 10 years ago [5]. Unidentified spots in 2-D gels or isoelectric focusing (IEF) analyses of transferrin subtypes [40-44] do not correspond to the fragments found in our study. This absence might be due to the relatively high theoretical isoelectric point values calculated for the human ( $\mathrm{pI}=7.95)$ and also the bovine C-terminus ( $\mathrm{pI}=8.44$ ), as many of the IEF gels employed in those studies covered a range of $\mathrm{pH} 4-7$. However, an exhaustive examination of various commercial sources and laboratory isolates of transferrins was not performed and is beyond the scope of this study. 


\section{Conclusions}

Transferrin proteins from a variety of species were characterized by mass spectrometry. CAD-MS for proteins as large as $79 \mathrm{kDa}$ transferrins yielded sequence informative products, albeit with limited sequence coverage. However, coupled with sequence searching programs, protein identification from top-down MS sequencing of intact proteins was possible. The present study highlights also the variety of tools developed and augmented over the past 10 years, when the $\mathrm{C}$-terminal fragment of transferrin was originally observed [5]. Iron-catalyzed cleavage was investigated as potentially responsible for generating 6-8 $\mathrm{kDa}$ fragments that appeared to originate from the C-terminus upon disulfide reduction. Although larger molecular weight fragments from both the $\mathrm{N}$ - and C-termini were produced in the presence of iron, the origin of the $6-8 \mathrm{kDa}$ C-terminal products was determined to lie elsewhere, rather from the presence of a transferrin population with a separate intermolecular disulfide-linked polypeptide that is released by disulfide reduction. Truncated versions of transferrin proteins have not been reported to date.

\section{Acknowledgments}

The authors especially appreciate experimental help from Mr. Kerry M. Wooding and Dr. James L. Kerwin. They acknowledge additional support in the operation of the ion trap mass spectrometer from Agilent Technologies. The authors also acknowledge support from the U.S. Department of Energy for funding the UCLA-DOE Laboratory of Genomics and Proteomics (DE-FC0387ER60615), the David Geffen School of Medicine at UCLA, and the UCLA Molecular Biology Institute. The UCLA Mass Spectrometry and Proteomics Technology Center was established and equipped with a generous grant from the W. M. Keck Foundation.

\section{References}

1. Fenn, J. B.; Mann, M.; Meng, C. K.; Wong, S. F.; Whitehouse, C. M. Electrospray Ionization for Mass Spectrometry of Large Biomolecules. Science 1989, 246, 64-71.

2. Karas, M.; Hillenkamp, F. Laser Desorption Ionization of Proteins with Molecular Masses Exceeding 10,000 Daltons. Anal. Chem. 1988, 60, 2299-2301.

3. Tanaka, K.; Waki, H.; Ido, Y.; Akita, S.; Yoshida, Y.; Yohida, T. Protein and Polymer Analyses up to $m / z$ 100,000 by Laser Ionization Time-of-Flight Mass Spectrometry. Rapid Commun. Mass Spectrom. 1988, 2, 151-153.

4. Harris, D. C.; Aisen, P. Physical Biochemistry of the Transferrins. Physical Bioinorganic Chemistry Series 5 (Iron Carriers, Iron Proteins), Loehr, T. M., Ed.; VCH Publishers: New York, NY, 1989; pp 239-351.

5. Loo, J. A.; Smith, R. D. Tandem Mass Spectrometry of Multiply Charged Proteins with Electrospray Ionization. Proceedings of the 40th ASMS Conference on Mass Spectrometry and Allied Topics; Washington, DC, June, 1992; pp 627-628.

6. Loo, J. A.; Edmonds, C. G.; Udseth, H. R.; Smith, R. D. Effect of Reducing Disulfide-Containing Proteins on Electrospray Ionization Mass Spectra. Anal. Chem. 1990, 62, 693-698.
7. Kim, K.; Rhee, S. G.; Stadtman, E. R. Nonenzymatic Cleavage of Proteins by Reactive Oxygen Species Generated by Dithiothreitol and Iron. J. Biol. Chem. 1985, 260, 15394-15397.

8. Goldshleger, R.; Pachornik, G.; Mehlman, T.; Benjamin, M.; Merhav, D.; Karlish, S. J. D.; Shainskaya, A. Application of a "Top-Down" Approach for the Analysis of Selective $\mathrm{Fe}^{2+}$ Catalyzed Oxidative Cleavages of Na.K-Atpase from Pig Kidney by Mass Spectrometry. Implication for the Energy Transduction Mechanism. Proceedings of the 50th ASMS Conference on Mass Spectrometry and Allied Topics; Orlando, FL, June, 2002.

9. Luo, S.; Ishida, H.; Makino, A.; Mae, T. Fe ${ }^{2+}$-Catalyzed SiteSpecific Cleavage of the Large Subunit of Ribulose 1,5Bisphosphate Carboxylase Close to the Active Site. J. Biol. Chem. 2002, 277, 12382-12387.

10. Hlavaty, J. J.; Benner, J. S.; Hornstra, L. J.; Schildkraut, I. Identification of the Metal-Binding Sites of Restriction Endonucleases by $\mathrm{Fe}^{2+}$-Mediated Oxidative Cleavage. Biochemistry 2000, 39, 3097-3105.

11. Godson, G. N.; Schoenich, J.; Sun, W.; Mustaev, A. A. Identification of the Magnesium Ion Binding Site in the Catalytic Center of Escherichia coli Primase by Iron Cleavage. Biochemistry 2000, 39, 332-339.

12. Goldshleger, R.; Karlish, S. J. Fe-Catalyzed Cleavage of the $\alpha$ Subunit of Na/K-ATPase: Evidence for Conformation-Sensitive Interactions between Cytoplasmic Domains. Proc. Natl. Acad. Sci. U.S.A. 1997, 94, 9596-9601.

13. Haber, F.; Weiss, J. Proc. Royal Soc. London Ser. A 1934, 147, 332-351.

14. McCord, J. M.; Day, E. D., Jr. Superoxide-Dependent Production of Hydroxyl Radical Catalyzed by Iron-EDTA Complex. FEBS Lett. 1978, 86, 139-142.

15. Winterbourn, C. C. Lactoferrin-Catalyzed Hydroxyl Radical Production. Additional Requirement for a Chelating Agent. Biochem. J. 1983, 210, 15-19.

16. Winterbourn, C. C. Comparison of Superoxide with Other Reducing Agents in the Biological Production of Hydroxyl Radicals. Biochem. J. 1979, 182, 625-628.

17. Motohashi, N.; Mori, I. Superoxide-Dependent Formation of Hydroxyl Radical Catalyzed by Transferrin. FEBS Lett. 1983, 157, 197-199.

18. Baldwin, D. A.; Jenny, E. R.; Aisen, P. The Effect of Human Serum Transferrin and Milk Lactoferrin on Hydroxyl Radical Formation from Superoxide and Hydrogen Peroxide. J. Biol. Chem. 1984, 259, 13391-13394.

19. von Bonsdorff, L.; Tolo, H.; Lindeberg, E.; Nyman, T.; Harju, A.; Parkkinen, J. Development of a Pharmaceutical Apotransferrin Product for Iron Binding Therapy. Biologicals 2001, 29, 27-37.

20. Mortz, E.; O'Connor, P. B.; Roepstorff, P.; Kelleher, N. L.; Wood, T. D.; McLafferty, F. W.; Mann, M. Sequence Tag Identification of Intact Proteins by Matching Tanden Mass Spectral Data Against Sequence Data Bases. Proc. Natl. Acad. Sci. U.S.A. 1996, 93, 8264-8267.

21. Meng, F.; Cargile, B. J.; Miller, L. M.; Forbes, A. J.; Johnson, J. R.; Kelleher, N. L. Informatics and Multiplexing of Intact Protein Identification in Bacteria and the Archaea. Nat. Biotechnol. 2001, 19, 952-957.

22. Johnson, J. R.; Meng, F.; Forbes, A. J.; Cargile, B. J.; Kelleher, N. L. Fourier-Transform Mass Spectrometry for Automated Fragmentation and Identification of 5-20 kDa Proteins in Mixtures. Electrophoresis 2002, 23, 3217-3223.

23. Smith, R. D.; Loo, J. A.; Barinaga, C. J.; Edmonds, C. G.; Udseth, H. R. Collisional Activation and Collision-Activated Dissociation of Large Multiply Charged Polypeptides and Proteins Produced by Electrospray Ionization. J. Am. Soc. Mass Spectrom. 1990, 1, 53-65. 
24. Loo, J. A.; Edmonds, C. G.; Smith, R. D. Tandem Mass Spectrometry of Very Large Molecules: Serum Albumin Sequence Information from Multiply Charged Ions Formed by Electrospray Ionization. Anal. Chem. 1991, 63, 2488-2499.

25. Loo, J. A.; Loo, R. R.; Udseth, H. R.; Edmonds, C. G.; Smith, R. D. Solvent-Induced Conformational Changes of Polypeptides Probed by Electrospray-Ionization Mass Spectrometry. Rapid Commun. Mass Spectrom. 1991, 5, 101-105.

26. Loo, J. A.; Edmonds, C. G.; Smith, R. D. Tandem Mass Spectrometry of Very Large Molecules. 2. Dissociation of Multiply Charged Proline-Containing Proteins from Electrospray Ionization. Anal. Chem. 1993, 65, 425-438.

27. Loo, J. A.; Edmonds, C. G.; Smith, R. D. Primary Sequence Information from Intact Proteins by Electrospray Ionization Tandem Mass Spectrometry. Science 1990, 248, 201-204.

28. Loo, J. A.; Quinn, J. P.; Ryu, S. I.; Henry, K. D.; Senko, M. W.; McLafferty, F. W. High-Resolution Tandem Mass Spectrometry of Large Biomolecules. Proc. Natl. Acad. Sci. U.S.A 1992, 89, 286-289.

29. Kelleher, N. L.; Lin, H. Y.; Valaskovic, G. A.; Aaserud, D. J.; Fridriksson, E. K.; McLafferty, F. W. Top Down Versus Bottom up Protein Characterization by Tandem High-Resolution Mass Spectrometry. J. Am. Chem. Soc. 1999, 121, 806-812.

30. Hofstadler, S. A.; Sannes-Lowery, K. A.; Griffey, R. H. Infrared Multiphoton Dissociation in an External Ion Reservoir. Anal. Chem. 1999, 71, 2067-2070.

31. Horn, D. M.; Zubarev, R. A.; McLafferty, F. W. Automated de Novo Sequencing of Proteins by Tandem High-Resolution Mass Spectrometry. Proc. Natl. Acad. Sci. U.S.A. 2000, 97, 10313-10317.

32. Ge, Y.; Lawhorn, B. G. El; Naggar, M.; Strauss, E.; Park, J. H.; Begley, T. P.; McLafferty, F. W. Top Down Characterization of Larger Proteins (45 Kda) by Electron Capture Dissociation Mass Spectrometry. J. Am. Chem. Soc. 2002, 124, 672-678.

33. McLafferty, F. W.; Horn, D. M.; Breuker, K.; Ge, Y.; Lewis, M. A.; Cerda, B.; Zubarev, R. A.; Carpenter, B. K. Electron Capture Dissociation of Gaseous Multiply Charged Ions by Fourier-Transform Ion Cyclotron Resonance. J. Am. Soc. Mass Spectrom. 2001, 12, 245-249.
34. Shevchenko, A.; Wilm, M.; Vorm, O.; Mann, M. Mass Spectrometric Sequencing of Proteins Silver-Stained Polyacrylamide Gels. Anal. Chem. 1996, 68, 850-858.

35. Nemeth-Cawley, J. F.; Rouse, J. C. Identification and Sequencing Analysis of Intact Proteins Via Collision-Induced Dissociation and Quadrupole Time-of-Flight Mass Spectrometry. J. Mass Spectrom. 2002, 37, 270-282.

36. Demirev, P. A.; Ramirez, J.; Fenselau, C. Tandem Mass Spectrometry of Intact Proteins for Characterization of Biomarkers from Bacillus cereus T Spores. Anal. Chem. 2001, 73, 5725-5731.

37. Hall, D. R.; Hadden, J. M.; Leonard, G. A.; Bailey, S.; Neu, M.; Winn, M.; Lindley, P. F. The Crystal and Molecular Structures of Diferric Procine and Rabbit Serum Transferrins at Resolutions of 2.15 and $2.60 \AA$, Respectively. Acta Crystallogr. D. Biol. Crystallogr. 2002, 58, 70-80.

38. Haugland, R. P. Handbook of Fluorescent Probes and Research Products, 9th ed. Molecular Probes, Inc.: Eugene, 2002; p 751.

39. Smith, R. C.; Wyard, S. J. Spatial Distribution of Free Radicals Studied by Electron Spin Resonance (EPR). Nature 1961, 191, 897-898.

40. Budowle, B. Improved Separations of the Common Transferrin Variants in Gels Containing pH 5-7 Ampholines and Hepes. Electrophoresis 1987, 8, 210-212.

41. Petren, S. Determination of Transferrin Isoproteins in Human Cerebrospinal Fluid Using Isoelectric Focusing and Zone Immunoelectrophoresis Assay. Electrophoresis 1987, 8, 515-517.

42. Manabe, T.; Takahashi, Y.; Okuyama, T. Identification of Bovine Fetal and Adult Serum/Plasma Proteins by TwoDimensional Electrophoresis and Immunochemical Staining. Electrophoresis 1987, 8, 573-579.

43. D'Alessandro, A. M. D'; Andrea, G.; Oratore, A. Different Patterns of Human Serum Transferrin on Isoelectric Focusing Using Synthetic Carrier Ampholytes or Immobilized pH Gradients. Electrophoresis 1988, 9, 80-83.

44. Sebetan, I. M.; Oshida, S.; Akaishi, S. Transferrin (Tf) Polymorphism: An Analysis by Isoelectric Focusing. Forensic Sci. Int. 1982, 19, 281-286. 